\title{
Ethnicity and Social Critique in Tony Hilleman's Crime Fiction
}

\section{Šárka Bubíková}

American mystery writer Tony Hillerman (1925-2008) achieved wide readership both within the United States and abroad, and, significantly, within the US both among white Americans and Native Americans. This article discusses Hillerman's detective fiction firstly within the tradition of the genre and then focuses on particular themes and literary means the writer employs in order to disseminate knowledge about the Southwestern nations (tribes) among his readers using the framework of mystery (crime) fiction. Hillerman's two literary detectives Lieutenant Foe Leaphorn and Sergeant fim Chee, both of the Navajo Tribal Police, are analyzed and contrasted with female characters. Finally, the article analyzes the ways in which Hillerman makes the detectives' intimate knowledge of the traditions, beliefs and rituals of the southwestern tribes and of the rough beauty of the landscape central to the novels' plots, and how he presents cultural information.

\section{Keywords}

Ethnic crime fiction; Tony Hillerman; Navajo Tribal Police; Southwestern landscape; hozho principle of harmony; Navajo mythology

In 1992, the editors of The English fournal asked American high school students who their favorite author of detective fiction was. They naturally expected that famous classics such as Arthur Conan Doyle, Dorothy Sayers, Ross MacDonald, and Dashiell Hammett would receive the highest scores and were greatly surprised that it was Tony Hillerman (1925-2008) who ranked as unquestionably the most popular. Apart from praising Hillerman's ability to create suspenseful and thrilling stories, the students also claimed that thanks to his fiction, they learned about Native Americans (BFN 91).

Hillerman received many awards and prizes for his writing. He served as the president of the Mystery Writers of America, he was presented with the Edgar and the Grand Master Awards for mystery writing, the Center for the American Indian's Ambassador Award as well as the Silver Spur Award for the best novel 
set in the West. Of all the honors and awards he received, however, Hillerman cherished most the fact that he was named an honorary member of the Navajo Nation and that he received the Navajo Tribe's Special Friend Award. Such acceptance by the Navajo people confirmed that Hillerman's treatment of Native American cultural material is accurate enough and sensitively handled, in other words that Hillerman succeeded not only among his target audience (white Americans) but among the people of whom he wrote ${ }^{1}$.

Despite his popularity among readers, Hillerman is not very frequently discussed by literary critics; his writing is covered in several books mapping the phenomenon of multicultural or ethnic crime fiction, and discussed in individual scholarly articles either focusing on particular novels or comparing them to other writers' fiction ${ }^{2}$. This article attempts to contribute to the discussion on Hillerman's fiction by showing what literary means, themes and motifs the writer uses throughout his fiction in order to successfully provide cultural information and social commentary as well as critique within the framework of a detective story.

Hillerman's detective fiction can be classified as police procedural but it is distinct in several aspects, including its setting and the characters of his police crime investigators. Although the majority of late twentieth century detective fiction employs an urban setting, Tony Hillerman sets his novels in the vast American Southwest, an area which comprises almost 30 thousand square miles (or 70 thousand square kilometers), but with only some 200 thousand inhabitants residing there including several Native American reservations. Another important distinctive feature of Hillerman's detective novels are his protagonists, both members of the Navajo Tribal Police (currently the Navajo Nation Police). The crimes (usually murders) they investigate, happen on reservation land and the victims, suspects and sometimes culprits are also Native Americans.

And yet, when Hillerman - an Oklahoma-born writer with German and English ancestry who fell in love with the Southwest when he moved there to study at the University of New Mexico - submitted his first novel to a publishing house, its editor recommended that Hillerman should rather stick to non-fiction. When asked if the story could be re-written, the editor suggested that if only Hillerman deleted all the "Indian stuff", it would make a publishable story (Hillerman, Seldom Disappointed 3). Hillerman submitted the manuscript to a different publisher instead, this time to Harper\&Row and they, on the contrary, appreciated "all the Indian stuff" and even recommended 
that Hillerman turn the tribal policeman from a marginal character into the central one. In this way, Lieutenant Joe Leaphorn came into existence, a complex character that embodies many of the issues of multicultural postmodern America.

\section{Hillerman's detectives}

In the character of Leaphorn, Hillerman illustrates the tensions and difficulties of a person who has to negotiate between two very different worlds, and has to bridge diverse cultures, traditions, and belief systems. While constantly learning how to operate in the white world, he attempts to preserve his own unique identity. Joe Leaphorn is a Navajo who studied anthropology at the University of Arizona and after a few years of service in the FBI he returns back to his Navajo reservation home as a member of the tribal police.

Although Leaphorn grew up on the reservation, he claims to be an agnostic, skeptical towards many of the Navajo beliefs, which he tends to consider as superstitions. He has "no tolerance for witchcraft or anything about it - for those who believed in witches, or stories about skinwalkers, corpse sickness, the cures for the same, and everything connected with the Navajo Wolves" (Hillerman, Skinwalkers 74) ${ }^{3}$. Nevertheless, he respects the Navajo traditional life. For example, when Leaphorn visits a Kinaalda, a female initiation ceremony, he "fe[els] a fierce pride in his people, and in this celebration of womanhood" (Hillerman, Listening Woman 146) while observing it. He is also saddened by the gradual disappearance or disruptions of traditional ways, for example, when he notes the importance of a police presence at an Enemy Way ceremony: "The white man's machines made it easy to travel about and people came just to visit and fool around. In the old days there wouldn't have been any drinking and gambling at a ceremonial like this" (Hillerman, The Blessing Way 95).

As a detective, Leaphorn is of the honest, incorruptible type who would never compromise his integrity. He is well equipped for his job precisely because he is knowledgeable about both the white man's world and about the world of Southwestern Native tribes (his education in anthropology). He employs traditional methods of investigations, logic and rational deductions, as well as makes use of his deep understanding of his people, of intimate knowledge of the landscape and topography, and he combines this with 
extraordinary tracking skills. Thus, for example, Leaphorn double-checks the scene of one murder, reasoning that he as a Navajo "could find tracks where a Zuñi couldn't" (Hillerman, Dance Hall of the Dead 15).

Later Hillerman created another detective, the younger Officer Jim Chee (first introduced in People of Darkness, in later works promoted to the rank of Sergeant), who shares with Leaphorn the affiliation with the Navajo Tribal Police as well as an academic education in anthropology received at the University of New Mexico. Contrary to Leaphorn, Chee remains a traditional Navajo and he even trains to become a shaman, a Hatatii. Unlike the rational and skeptical Leaphorn, Chee is an intuitive, emotional, and passionate romantic, "a man who follow[s] dreams" (Hillerman, A Thief of Time 227). He contradicts Leaphorn's disbelief in witches and skinwalkers by contending that "the origin story of the Navajos explained witchcraft clearly enough, and it was a logical part of the philosophy on which the Dinee [the Navajos] had founded their culture. If there was good, and harmony, and beauty on the east side of reality, then there must be evil, chaos, and ugliness to the west" (Hillerman, Skinwalkers 75).

Nevertheless, Jim Chee, too, is a contemporary Native American and must therefore learn to function in two worlds. While Leaphorn combines elements of both cultures in his professional life, for Chee living in-between the two cultures it often involves an either/or choice. Such an attitude was suggested to Chee by his uncle, the traditional medicine man from whom Chee hopes to learn to be a singer. The uncle asked Chee to study the white man's world first and then to make a decision if he "[w]ould follow the white man's way or would he be a Navajo?" (Hillerman, People of Darkness 85 ). Although Chee applied for admission into the FBI, he is acutely aware that he cannot be "both a Navajo medicine man and an FBI agent," that he cannot possibly be just a Navajo and at the same time an FBI agent nor even "a Navajo away from the People [other Navajos]" (Hillerman, People of Darkness 108). Chee's uneasy positioning between two cultures is symbolized by his dwelling - he lives in a trailer which is neither the traditional Navajo hogan nor a typical American site built house.

Although Leaphorn often becomes impatient with his people for their witchcraft superstitions, he nonetheless respects and follows the main Navajo life principle, hozho, which can best be described as harmony with oneself and with the world around. This metaphysical grounding is in Leaphorn's view unique to Navajos and it helped them survive in the changing world. 
Leaphorn sums up the history and fate of the southwestern tribes in these words: "Thus while the Kiowas were crushed, the Utes reduced to hopeless poverty, and the Hopis withdrawn into the secret of their kivas, the eternal Navajo adapted and endured" (Hillerman, Listening Woman 147). Leaphorn also uses the concept of harmony as a guiding principle in his investigations, as he always tries to find out how things and events fall into place and form a pattern. He thus combines western rationality with Navajo metaphysics to arrive at a solution to the mysteries he investigates. This is well symbolized by Leaphorn's love for maps, which he uses in an "endless hunt for patterns, sequences, order - something that would bring a semblance of Navajo hozho to the chaos of crime and violence" (Hillerman, Coyote Waits 150). Elsewhere Hillerman notes: "Given quiet, and a little time, Leaphorn's mind was very, very good at this process of finding logical causes behind apparently illogical effects" (Hillerman, Skinwalkers 13), even that "the precise application of logic" brought Leaphorn "abstract pleasure" while he found "patternless chaos [...] painful" (Hillerman, Dance Hall of the Dead 75).

In Hillerman's novels, the offenders and sometimes the victims are people who do not live in harmony; if they are Navajos they are estranged from their traditions, for example, in Blessing Way the criminal is an urban Navajo who has lost his roots in traditional values and in the urban jungle found only greed to replace them, while one of the victims is "just another poor soul who didn't quite know how to be a Navajo and couldn't learn to act like a white" (70); in Listening Woman the culprit disturbs sacred sand paintings; in Dance Hall of the Dead the murderer commits a hideous sacrilege against the Zuñis. Even excessive professional ambition is out of harmony and can lead to crime (as in A Thief of Time). An understanding of how things and people get out of harmony is at the same time the necessary first step on the way to the reestablishment of natural order and beauty.

For Leaphorn and Chee, the concept of hozho provides a spiritual grounding as well which helps to shield them from the specific temptations of police work, particularly from using questionable or even downright illegal means during an investigation, a motif not infrequent in American crime fiction. However, for the Navajo police officers, such a blurring of the boundary between a criminal and a criminalist is unacceptable; it is out of the question because it would throw things off their natural balance. 


\section{Female characters}

The characters of the two policemen are complemented by their female counterparts. Joe Leaphorn is married to intuitive, emphatic Emma, who is deeply rooted in Navajo spiritual traditions and who hardly ever sets foot outside of Navajo land.

The difficulty of intercultural relationships is represented by Chee's painful and tense love affair with Mary Landon, a white woman from a small town in Wisconsin who comes to the reservation as a teacher. When Chee meets Mary Landon for the first time, he notices her "soft blond hair $[. .$.$] and large blue$ eyes" (Hillerman, People of Darkness 9o) and concludes that she is the type on "the racial/ethnic guilt trip" and that she is interested in "Indian males" because she is trying to find out if they are "really any different from the blond boys" she had grown up with (9o). At that point, Mary "liked teaching Navajo children" and "hoped to learn Navajo, but it was hard to pronounce and so far she could speak only a few phrases" (104).

Later on, she gives up learning the language and openly wishes Chee to take a job with the FBI and move out of the reservation so that they will be able to raise their children as white Americans. Chee, however, wants to stay on the reservation because to him that is the only place where he can be a Navajo. Therefore, there is no common ground for Chee's and Mary's common future; it is another of the either/or choices Chee faces:

Either he stayed with the Navajo Police or he took a job off reservation. Either he stayed Navajo or he turned white. Either they raised their children in Albuquerque, or Albany, or some other white city as white children, or they raised them on the Colorado Plateau as Dinee. Halfway was worse than either way. Chee had seen enough of that among displaced Navajos in the border towns to know. There was no compromise solution. (Hillerman, The Ghostway 8)

In $A$ Thief of Time, Chee describes the choice in these words: "Did I want her enough to quit being a Navajo?" (125). In the white man's world, Chee thinks, he could "still be a Navajo in the sense of blood, but not in the sense of belief" (205) and therefore he would be "an alien living in exile" (205).

After the painful break with Mary Landon, Jim Chee meets Janet Pete, a Navajo lawyer with whom he shares a cultural heritage. But while his adherence to Navajo traditions prompts him to return from the "big world" 
of FBI investigations and to join the Navajo Tribal Police, Janet Pete moves in the opposite direction - she leaves the reservation for the opportunity to build her career with a law firm in Washington, D.C. Chee tries to explain her departure from the reservation by the fact that she was "Navajo only by blood and birth" and had not been raised "on the Reservation in the Navajo Way" (Hillerman, Coyote Waits 143). Thus Janet Pete represents one in the long string of uprooted Native American literary characters. Janet Pete wants Chee to change, to move out of the reservation and Chee becomes aware that "Janet had seen him as a rough diamond she's found in the West who would become a gem in her urbane, Ivy League East after a little polishing" (Hillerman, The Wailing Wind 247).

The relationship with a culturally uprooted or estranged Navajo woman is therefore as equally unsuccessful as the one with a white woman. Finally, Jim Chee marries Officer Bernadette (Bernie) Manuelito, a Navajo who wants to be a Navajo and wants to live on the Reservation because it is her home as well as it is Chee's. By the string of Chee's acquaintances, Hillerman seems to suggest that integration is preferable to assimilation because assimilation always inevitably leads to a loss of ethnic roots and identity.

\section{Landscape}

The Navajos call themselves Diné and their home is called in the Navajo language Dinétah which means "among the people" or "among the Navajo" as well as the Navajo heartland; thus in their view, the people, identity, culture, and landscape are closely interconnected. To highlight this aspect of Navajo culture, Hillerman devotes great attention to the landscape in his novels. Therefore, just as the English countryside is the hallmark of much of Agatha Christie's detective fiction and Los Angeles of Raymond Chandler's, so the landscape of the American Southwest is an inseparable aspect of Hillerman's crime fiction.

The arid country with its canyons, arroyos, mesas, ridges, with its sparse vegetation of junipers, yuccas, low piñon pines and ponderosas is not just a background setting but a participant in the novels' plots. Leonard Engel claims that the landscape is even inseparable from the characters' identity: "Leaphorn's job as a Navajo cop [...], indeed, his whole being and sense of self, form an intimate relationship with the land" (117).

Hillerman's Navajo characters pay attention to weather, particularly to 
clouds and wind looking for signs of approaching rain, because it is something very important in the dry land. In Skinwalkers Hillerman explains: "Like all people who live a lot out of doors and whose culture depends upon the weather, Leaphorn was a student of the sky" (238). Or "[n]ormally rain provoked jubilation in Chee - a feeling natural and primal, bred into drycountry people" (Hillerman, Coyote Waits 10). There are many observations of weather in the novels, such as: "Cumulus clouds climbing the sky over the Chuskas were tall enough to form the anvil tops that promised rain" (Hillerman, Skinwalkers 51). "The shadow of the thunderhead over the Chuskas had moved across the Shiprock landscape. [...] But it wouldn't rain" (58). "A flash of lightning on the eastern horizon - much too distant to hear the thunder and the wrong direction to threaten any rain" (Hillerman, $A$ Thief of Time 5). Some comments on the climactic specifics of the area are even presented in a comic way. For example, Leaphorn buys an umbrella when an investigation brings him to rainy New York. He then walks under it "tremendously self-conscious, thinking he would own the only umbrella in Window Rock, and perhaps the only umbrella on the reservation, if not in all of Arizona" (Hillerman, A Thief of Time 184).

By the plentitude of mentions of the weather conditions, Hillerman alerts his readers to the unique quality of the semi-desert. However, he does not simply familiarize his readers with this rather exotic corner of the USA, he, at the same time, teaches them to respect and appreciate it by showing how it is respected and appreciated by its inhabitants.

Descriptions of landscape and of weather changes are not used to highlight or to echo a character's mood or the story's atmosphere; on the other hand, the landscape's spaciousness, beauty, stability and ancient character frequently contrast the transiency of human lives, chaos of their actions, or ugliness of their violent acts. As Engel points out, the "landscape is both beautiful and forbidding" and is "imbued with a naturalistic indifference" (116). The reader is constantly reminded of the spaciousness and larger-than-life character of the landscape by frequent brief remarks interspersed in the narratives, such as: "the infinity of sagebrush" (Hillerman, A Thief of Time 9o), "the rocky barrens south of Caso del Eco" (214), "the bare stoniness of Gothic Creek" (214), "an infinity of New Mexico's empty corner" (Hillerman, The Wailing Wind 3), "the eons of time" (Hillerman, Coyote Waits 247), "a vast landscape of greys and tans" (188), a road wandering "toward infinity" (Hillerman, Sacred Clowns 321); or comments such as "Good manners demanded the disclaimer of hunger from a wayfarer, but the topography of the Colorado 
Plateau made it an obvious lie. Out here there was literally no place to stop to eat" (Hillerman, $A$ Thief of Time 16o). While the Navajo characters are well aware of the dangers of the dry country, they also appreciate its beauty and find it spiritually nurturing, as, for example, Officer Bernie Manuelito taking a rest at a lookout spot: "This immensity, dappled with cloud shadows and punctuated with assorted mountain peaks, was enough to lift the human spirit" (Hillerman, The Wailing Wind 3).

It is often the policemen's intimate knowledge of the topography which helps to solve the mysteries. Thus, for example, Chee narrows down a search for a site despoiled by an illegal dealer in Anasazi pots by knowing where the Anasazi had built their homes. Leaphorn's ability to read the landscape and his awareness of the importance of live water sources adds in tracking a lost child in Dance Hall of the Dead or locating a runaway suspect in $A$ Thief of Time. In his book review, Nicholas H. Allison summarized Hillerman's ability to include landscape into his mysteries poignantly by saying: "In a world teeming with 'sense of place' mysteries - set in Seattle, Alaska, the Arizona desert, or Chicago - it can be a shock to return to Hillerman, who started it all, and realize just how superior he is to the rest of the pack".

Very often Hillerman points out the fact that Navajos live in harmony with their land and adopt their ways to suit it rather than change the land to suit them. His novels also implicitly warn against land mismanagement. In $A$ Thief of Time, a Christian Navajo uses the damage of a sacred place as an argument in his missionary attempts, but the scene implicitly points to the connection between the landscape and Native culture and to the fact that the devastation of one destroys the other: " $[\mathrm{R}]$ emember how that holy place look[s now]. Truck road runs up there. It's got radio towers built all over the top of it. Oil companies built 'em. Whole forest of those antennae all along the top of our holy place. $[\ldots]$ I can't pray to the mountain no more. [...] Changing Woman left us. She's gone away..." (75). In The Wailing Wind, misdirection is deliberately given in order to lead gold prospectors away from potential deposits because "the worst thing that can happen to a tribe is to have whites discover gold deposits on the tribe's land" (89). And to illustrate the point, a Navajo character provides historical examples:

General Carlton thought we had a lot of gold in our mountains, so he had the army round us Navajos and move us away on that long walk to Bosque Redondo. They drove the Utes out of Colorado to get the gold in their mountains. And drove the tribes out of the Black Hills, and pretty 
much killed California Indians. Everywhere they find gold, they destroy everything for it. (50-51)

Greed is again and on a larger scale, presented as something out of harmony with the natural way of the world, and as an agent throwing everything else out of harmony, too. To be greedy is in contradiction to the Navajo concept of hozho and only brings about disaster. If a single person is greedy, it can result in a violent crime against another individual; if a nation is greedy, it results in crimes committed against another nation.

\section{Ethnic Dimension}

In his novels, Hillerman teaches his readers about Navajos (in most of the novels), about Hopis (for example, in The Dark Wind), Zuñis (in the Dance Hall of the Dead), the Pueblo people (in Sacred Clowns), and Anasazis (in $A$ Thief of Time). For this educational purpose he uses various literary means to disseminate information. From the point of view of the genre of detective fiction, knowledge of Native American traditions often provides key to solving a crime. For example, in Skinwalkers, Chee explains why he concluded the criminal must be a Navajo:

"Was the killer a Navajo?" Leaphorn asked. [...]

"Yes," [Chee] said. "Navajo." [...]

"Why Navajo?" [...]

"He didn't step over the body [...] When he walked down the arroyo, he took care not to walk where the water had run. [...] And when he crossed a snake's path he shuffled his feet. [...] Or do white men do that too?" (66).

In many cases, comparative cultural information is presented via an interaction between a Navajo and a white character. Thus, for example, when Chee goes out for the first time with Mary Landon, he introduces himself by describing his family background. Mary complains that instead of speaking about himself, Chee speaks about his relatives. Readers are presented with Chee's reaction which points to this cultural difference: Mary's complaint "surprised Chee. One defined himself by his family. How else? And then it occurred to him that white people didn't. They identified themselves by what they had 
done as individuals" (Hillerman, People of Darkness, 105). Hillerman then proceeds to having Chee elaborate on the difference in more detail in the ensuing discussion in which he explains to Mary how he would introduce her to his people. To her objection that he would talk about her using the word "woman" and not her personal name, Chee supplies another explanation: "That would be rude. $[. .].[$ A] mong traditional Navajos it's very impolite to say someone's name in their presence. Names are just reference words, when the person's not there" (106).

Occasionally, certain cultural observations presented by a character familiar with Native Americans are confirmed or corrected by a Navajo character. For example, an old Jewish trader McGinnis speculating about a murder case on the reservation, says to Leaphorn:

"I don't think a Navajo did it. [...] You Navajos will steal if you think you can get off with something, but I never heard of one going out to kill somebody. [...] That's one kind of white man's meanness the Navajos never took to. Any killings you have, there's either getting drunk and doing it, or getting mad and fighting. You don't have this planning in advance and going out to kill somebody like white folks. That right?" (Hillerman, Listening Woman 70)

And after McGinnis and Leaphorn give the idea some thought, they both arrive at the same conclusion: "Except maybe if somebody thought he was a Navajo Wolf [= witch]" (71). In this way, the reader learns about a typical Navajo attitude to violent crimes and to the possibility of committing one for metaphysical reasons (i.e., destroying a person who was thought to be a witch, therefore not really human).

In People of Darkness, a corpse is stolen from the hospital's morgue. A nurse concludes that it was stolen because "Indians usually don't want an autopsy", and although Chee does not contradict her, the correct information is nonetheless passed on to the reader in the form of Chee's inner thoughts:

Charley was a Navajo and most Navajos had even less distaste for autopsies than do whites. It was the Pueblo Indians who tended to resist autopsies. Their dead needed to be buried in the same cycle of the sun as their death. [...] But for most of the Navajo clans, death produced only a short-lived and evil ghost, and everlasting oblivion for the human consciousness. They had little sentiment for corpses. (150) 
Thus Navajo beliefs about death are outlined and at the same time contrasted with beliefs of other groups of Native Americans. Hillerman emphasizes the fact that Native American tribes are very diverse in their life styles, beliefs, traditions and history, thus cultural information is often imparted in a comparative way. Chee, for example, contrasts the origin mythology of Navajos with origin myths in the sacred texts of Christianity, Judaism, Buddhism and other religious traditions (Hillerman, The Wailing Wind 117, 119). Leaphorn compares Hopi traditions with those of Navajos, again pointing out the unique Navajo attitude to the natural environment: "The Hopis had held a rain dance on Sunday, calling on the clouds - their ancestors - to restore the water blessing to the land. [...] It was not a Navajo concept, this idea of adjusting nature to human needs. The Navajo adjusted himself to remain in harmony with the universe" (Hillerman, Listening Woman 44). Differences in the belief system between Navajos and Hopis are elucidated many times in The Dark Wind, between Navajos and the Pueblo people in Sacred Clowns.

Sometimes cultural information is simply stated as a narrator's comment or a character's thought, such as: "Navajos do not point at one another" (Hillerman, Skinwalkers 30). "No Navajo child [...] grew up without being told that the owl was the symbol of death and disaster" (Hillerman, The Wailing Wind 105). "Navajos are conditioned to polite silences, but [Leaphorn] had learned long ago that they put pressure on most belagaana [whites]" (228). "She didn't hold out her hand. [...] This touching of strangers was a white man's custom that some traditional Navajos found difficult to adopt" (Hillerman, A Thief of Time 139). She "let the silence live, Navajo fashion" (123). The boy indicated west "in the Navajo fashion by a twist of his lips" (204).

On occasions, the comment is handled in a longer and a more detailed way. Here are just a few examples out of many: When a Navajo character Joseph Begay in The Blessing Way reflects on his home, his thoughts contain information about how a site for a traditional hogan is selected and how the structure is then erected (40-42). Leaphorn, looking for a witness, visits an Enemy Way ceremonial and the ceremonial is described and explained as part of Leaphorn's observations (89-112). In The Dark Wind, a Hopi ceremonial is described and as part of it, an old myth is retold (5-7), similarly in Sacred Clowns Jim Chee's visit to a Kachina dance brings information on the Tano people's rituals and belief system and because a crime is committed during a Zuñi ceremony in The Dance Hall of the Dead, the ceremony is described and the underlining mythology is explained.

To add effectivity to Hillerman's attempts to raise awareness in his fiction, 
cultural information is sometimes conveyed in a paradoxical manner, contrary to what would be the readers' general expectations; for example, when Leaphorn cannot trace the whereabouts of a white person, the narrator simply states: "The last name on Leaphorn's list seemed to have vanished with time - apparently part of the nomadic movement of belagaana [white] families who follow jobs around the country" (Hillerman, The Wailing Wind 80 ). But stereotypically, white people would call Native Americans nomadic, and imagine them following the herds of buffalo around the country, which is not true for the Southwestern sedentary tribes, including the Navajo. The unusual association of white culture with a nomadic lifestyle alerts the reader both to an important and often unacknowledged aspect of our own modern lifestyle as well as to our tendency to see all Native American tribes as culturally homogenous and their lifestyle exemplified by Great Plains tribes such as the Apache.

Differences between white and Navajo cultures can be pointed out in the form of rhetorical questions such as: "Why did the white culture either cool things or heat them before consumption?" (Hillerman, Skinwalkers 37) or "What was it about white men that caused them to plant grass in places where grass couldn't possibly grow without them fiddling with it all the time?" (119). Voiced by Chee, such questions are perfectly justifiable because after all, Chee is studying the white people's ways in order to make a qualified decision whether to join the white man's world or remain a Navajo.

Occasionally, Hillerman employs a subplot to illustrate a point. Thus, for example, in Skinwalkers, an aspect of Navajo culture is developed into a story of a stray cat who appears near Jim Chee's trailer. At first, Chee simply observes its struggle for survival, then he "form[s] a habit of leaving out table scraps to feed it after heavy snow" and when drought arrives, he leaves out water for the cat (2). Eventually, he builds a cat flap into his trailer door and allows the cat to come inside. However, he feels "slightly uneasy [...] If he hadn't started this meddling, nature would have taken its normal course. [...] But Chee had interfered. And now Chee was stuck with a dependent" (3). When Leaphorn sees the cat in Chee's trailer, he concludes: "The cat was thin, bony; its muscles had the ropy look of wild predators. If it had, in fact, been a pampered pet, it had adapted well. It had got itself in harmony with its new life. Like a Navajo, it had survived" (62). And Chee, who opposed the white people's idea of animal pets as unnatural, is eventually surprised to find himself caring for the cat and hoping it would finally make "the transition from someone's property to self-sufficient predator" (223) or, in other words, "[h]e wanted the 
cat to endure" (223). However, in A Thief of Time, Chee admits that his stray cat experiment failed and he ships the cat to Mary Landon: "the abandoned white man's cat [goes] back to the white man's world, where there's more to eat and the coyote doesn't get you" (124). The subplot parallels Chee's difficult relationship with Mary Landon and again implies that assimilation does not really work: a pet cannot permanently turn into an independent wild animal just as Mary Landon cannot successfully change into a Navajo nor can Jim Chee become a white man.

Hillerman's crime fiction also provides a form of cultural and social critique. Hillerman often points to the ignorance of the white majority towards Native Americans, to the poverty on the reservation, as well as to historical wrongdoings and their long-term effects on the Native population and culture. For example, in A Thief of Time, even a police officer in Wisconsin "had a little trouble believing in the Navajo Tribal Police" (240). Reservation poverty is mentioned in Skinwalkers, when Chee recollects his sociology professor saying:

Modern dentistry had made crooked teeth an identifying mark of those who were born into the bottommost fringe of the American socioeconomic classes. Unstraightened teeth for the white trash, uncorrected birth defects for the Navajo. Or, to be fair, for those Navajos who lived outside of reach of the Indian Health Service. $\left(35^{-6}\right)$

In Coyote Waits, an American Studies professor expresses her anger at naming a mountain pass after Colonel John Macrae Washington 4 and compares it to "naming a mountain pass in Israel after Adolf Hitler" (203). It is very likely that alerting American readers to the issue contributed to the tribe's struggle to have the pass renamed, which took place in 1992. The Narbona Pass honors the name of a respected Navajo elder who was killed and scalped by US militiamen in 1849 during peace negotiations with Colonel Washington, Governor of New Mexico at the time.

Talking God opens with a Smithsonian Institute spokesperson who defends the right of the museum to exhibit original skeletons of Native Americans rather than their plaster casts (as suggested by an anthropologist supporting tribal claims to re-bury the bones) "because the public has the right to expect authenticity" (7) and thus it introduces the controversial issue of the long-time western practice of exhibiting human relics in museums. To point out a double-standard in the western attitude to bones, Hillerman has the 
Smithsonian Institute spokesperson receive a parcel containing the bones of her grandparents dug up in a New England graveyard. The parcel includes a letter asking her to accept "these two authentic skeletons for authentic display", ensuring her that the sender "used authentic anthropological methods to locate the burials of authentic white Anglo types" (8). The motif is developed into a subplot revolving around the issue of the rights of indigenous people to artefacts they feel were stolen from them by whites and put up on display in museums across the USA and Europe.

On several occasions in his novels, Hillerman mentions the problem of illegal digging, i.e., archaeological and anthropological research done in officially prohibited sites. He shows that it is not only financial greed (the illicit trade in artefacts) but sometimes also professional greed, a desire to uncover something unique and thus secure for oneself a respected position among fellow professionals (academics) which leads to such practice. Again, these small scale crimes stand for much larger historical wrongdoings; as an individual archeologist shows lack of respect for laws protecting certain burial sites, the white culture has often showed little respect to Native American peoples. Wayne Templeton summarizes this aspect of Hillerman's work when he states: "Hillerman uses crimes as a metaphor for crime - small for large - and has created detectives whose main purpose is not solving the lesser crimes but, constantly pointing out the larger ones and revealing how they continue to victimize" (39). History is undeniably interwoven in the fabric of the present day, and past wrongdoings can still cast their shadow over the present. However, becoming aware of it is the first, and a necessary, step in any attempt to rectify the wrongs or to re-establish Navajo harmony.

\section{Conclusion}

This article attempted to show the scope of issues Tony Hillerman covered in his crime fiction without compromising the genre's entertaining and thrilling dimension. In fact, he has succeeded in raising awareness about the contemporary lives of Southwestern Native Americans and their country by carefully interspersing ethnological, geographical and historical-cultural knowledge into well-crafted suspense stories. While readers are thrilled by the former elements of Hillerman's fiction, the information about Native cultures and experiences has also come to be greatly appreciated, as, for example, the respondents of the afore-mentioned 1992 survey confirm by indicating that for 
them, part of the appeal of Hillerman's novels was their rich cultural material. Nowadays, Hillerman's novels are read both by detective fiction fans and by those eager to learn about the Navajo and their land. Hillerman therefore achieved his objective of teaching white Americans (as well as readers abroad) about Southwestern Native Americans, their traditional and contemporary lifestyles, belief systems, history, traditions and rituals, as well as their land. At first glance, it may seem paradoxical that a genre which generally deals with the disruption and final re-establishment of the social status quo and has as its primary aim thrilling and entertaining its readers could also instruct. However, Michael O'Hear and Richard Ramsey point out that in fact "detective stories [are] fundamentally suitable for didactic purposes. Their protagonists are after all students bent on learning the truth, and the genre has indeed been used to enlighten" (95). Hillerman's novels confirm this assertion with their rich Native American lore.

\section{Notes}

1. Several critics have pointed out a few shortcomings in the cultural information Hillerman provides, for example, Ernie Bulow, author of Navajo Taboos and a teacher who, as the critic's Amazon.com web page claims, taught the first Native American Literature course in the US in 1971, lists Hillerman's Navajo culture inaccuracies in Talking Mysteries: A Conversation with Tony Hillerman (University of New Mexico Press, 2004) but also adds that it does not diminish Hillerman's storytelling achievements. Maureen Reddy states that the amount of "anthropological description" makes it clear that Hillerman assumes a white audience (170) and holds Hillerman's outsider position against him claiming that despite his respect for American Indians, he "nonetheless participates in and benefits from the long-established appropriation of Indian culture" (169) without supporting her claim by textual evidence from Hillerman's work.

2. For example, Hillerman is briefly mentioned in Maureen T. Reddy's Traces, Codes and Clues: Reading in Crime Fiction, 2002, and a few plot overviews are provided in Ray Browne's Murder on the Reservation: American Indian Crime Fiction: Aims and Achievements, 2004. Leonard Engel discusses The Blessing Way, Dance Hall of the Dead and Listening Woman in context of the Western genre in his 1993 article in Western American Literature, while a more thorough and insightful study by Wayne Templeton appears in the collection of essays Multicultural Detective Fiction: Murder from the "Other" Side, 1999. Jane S. Bakerman in her 1981 Clues article focuses on Hillerman's Dance Hall of the Dead and Listening Woman, adding People of Darkness and The Dark Wind in her 1984 MELUS article, Samuel Coale compares Hillerman's The Dark Wind and Amanda Cross's The Players Come Again in his 1995 Clues article, while Allison Goelder compares Hillerman and Walter Mosley in a chapter in Sleuthing Ethnicity: The Detective in Multiethnic Crime Fiction, 2003. Several books of photographs (by Hillerman and other photographers) were published to illustrate the beauty of the landscape Hillerman set his mysteries 
in, such as Tony Hillerman's Landscape: On the Road with Chee and Leaphorn, 2009, by Hillerman's daughter Anne Hillerman.

3. Hillerman even adds two possible explanations for Leaphorn's attitude - one in the form of a rumor connected to an old case, the other one bringing in legendary Navajo leader Chee Dodge and his claim that this was not an original part of Navajo mythology but was added during the captivity of the Navajo at Fort Sumner in the mid- $19^{\text {th }}$ century.

4. Washington participated in wars against the Creek and Seminole Indians in Florida as well as in the removal of the Cherokee from their traditional lands in the American South to reservations in Oklahoma.

\section{Works Cited}

Allison, Nicholas H. "Hunting Badger book review." Amazon.com Review. 28 September, 2010. Web. 2 April, 2016.

BFN. "Booksearch: Favorite Detective Story Writers: From Poe to the Present." The English fournal 81 (2) 1992: 91-95. Print.

Engel, Leonard. "Landscape and Place in Tony Hillerman's Mysteries." Western American Literature 28.2 (Summer 1993): 111-122. Print.

Hillerman, Tony. Dance Hall of the Dead. 1973. New York: Harper Paperbacks, 2009. Print.

--. Listening Woman. 1978. New York: HarperTorch Paperbacks, 2002. Print.

---. People of Darkness. 1980. New York: Harper Paperbacks, 1991. Print.

---. Sacred Clowns. 1993. New York: HarperTorch Paperbacks, 2001. Print.

--. The Dark Wind. 1982. New York: Harper Paperbacks, 2011. Print.

---. The Ghostway. 1984. New York: HarperTorch Paperbacks, 2002. Print.

---. Skinwalkers. 1986. New York: HarperTorch Paperbacks, 2002. Print.

---. Talking God. 1989. New York: Harper Paperbacks, 1991. Print.

--. Coyote Waits. 1990. New York: HarperTorch Paperbacks, 2010. Print.

--. Seldom Disappointed. A Memoir. Harper Perennial, 2001. Print.

--. The Wailing Wind. 2002. New York: HarperTorch, 2003. Print.

O'Hear, Michael, and Richard Ramsey. "The Detective as Teacher: Didacticism in Detective Fiction." Clues: A fournal of Detection 21.2 (Fall/Winter 2000): 95-104. Print.

Reddy, Maureen T. Traces, Codes and Clues: Reading in Crime Fiction. Rutgers University Press, 2002. Print.

Templeton, Wayne. "Xojo" and Homicide: The Postcolonial Murder Mysteries of Tony Hillerman." Multicultural Detective Fiction. Ed. Adrienne Johnson Gosselin, New York and London: Garland Publishing, 1999. 37-59. Print. 
ŠÁRKA BUBÍKOVÁ is Associate Professor and the Head of the Department of English and American Studies at the University of Pardubice, Czech Republic. Specializing in modern American literature and Anglophone literature for children and youth, her research interests include representations of childhood and coming of age, the Bildungsroman, literary canon and contemporary ethnic literature. She has published a book (in Czech) examining the American literary canon (2007) and another on the influence of the changing concept of childhood on literary production for children (2009). She has co-authored Literary Childhoods: Growing Up in British and American Literature (2008) and has published numerous articles as well as a novel about Czech-American culture clashes, Smaragdové město [Emerald City] (2006). In 2010, she was a Fulbright research scholar at Amherst College, Amherst, MA. In 2012, she was a visiting scholar at the University of California in Santa Barbara, CA. She is the founding editor of the American and British Studies Annual.

Sarka.Bubikova@upce.cz 